\title{
Bacterial alginate metabolism: an important pathway for bioconversion of brown algae
}

\author{
Lanzeng Zhang, Xue Li, Xiyue Zhang, Yingjie Li* and Lushan Wang
}

\begin{abstract}
Brown macroalgae have attracted great attention as an alternative feedstock for biorefining. Although direct conversion of ethanol from alginates (major components of brown macroalgae cell walls) is not amenable for industrial production, significant progress has been made not only on enzymes involved in alginate degradation, but also on metabolic pathways for biorefining at the laboratory level. In this article, we summarise recent advances on four aspects: alginate, alginate lyases, different alginate-degrading systems, and application of alginate lyases and associated pathways. This knowledge will likely inspire sustainable solutions for further application of both alginate lyases and their associated pathways.
\end{abstract}

Keywords: Alginate, Alginate lyase, Alginate-utilising systems, Application of alginate lyases, Metabolic engineering

\section{Background}

Based on the medium-variant projection, the world's population of 7.7 billion in mid-2019 is estimated to reach around 8.5 billion in 2030, 9.7 billion in 2050, and 10.9 billion in 2100 [1]. Therefore, it is urgent to find alternative renewable energy sources. Marine macroalgae (seaweeds), including green, red and brown macroalgae, have attracted attention as an alternative feedstock for the production of both biofuels and chemicals due to their high content of suitable polysaccharides, largescale cultivation, and no requirement for arable land, freshwater or fertiliser [2]. Compared with green macroalgae that are mainly composed of relatively easily fermentable glucans, utilisation of red and brown macroalgae is more difficult because some members of their major polysaccharides are not easily fermented, such as 3,6-anhydro-L-galactose in red macroalgae and alginate in brown macroalgae. In recent decades, countless enzymes have been identified for degradation of the major carbohydrates in red and brown macroalgae, and

\footnotetext{
*Correspondence: yingjie.li@sdu.edu.cn

State Key Laboratory of Microbial Technology, Shandong University, Qingdao 266237, China
}

the seaweed-derived products are widely used in different fields, as summarised in several reviews [3-6]. For example, alginates show a number of applications in biomedical science and engineering due to their favourable properties, such as wound dressing, drug delivery, tissue engineering, and other applications [4]. In addition, the degradation products of alginate polymers-alginate oligosaccharides (AOS) have also shown health beneficial effects, such as immunomodulatory, antimicrobial, antioxidant, and other activities [3]. Moreover, advances in metabolic engineering allow us to convert these major carbohydrates to ethanol by expressing a complete biosynthesis pathway in a single microbial host $[7,8]$.

In this review, we discuss recent progress in the field, with emphasis on bacterial alginate degradation in vitro and in vivo, and particular focus on alginate, alginate lyases, microbial strategies for alginate degradation, and application of alginate lyases and alginate-degrading pathways.

\section{Alginate \\ Alginate is a linear anionic polysaccharide that forms the cell wall in brown macroalgae and some red algae [9]. It is also synthesised by some alginate-producing microor- ganisms (e.g. Pseudomonas [10] and Azotobacter [11]).} original author(s) and the source, provide a link to the Creative Commons licence, and indicate if changes were made. The images or other third party material in this article are included in the article's Creative Commons licence, unless indicated otherwise in a credit line to the material. If material is not included in the article's Creative Commons licence and your intended use is not permitted by statutory regulation or exceeds the permitted use, you will need to obtain permission directly from the copyright holder. To view a copy of this licence, visit http://creativecommons.org/licenses/by/4.0/. The Creative Commons Public Domain Dedication waiver (http://creativeco mmons.org/publicdomain/zero/1.0/) applies to the data made available in this article, unless otherwise stated in a credit line to the data. 
This process is usually under strict regulatory control [12-14]. Unlike alginates present in brown macroalgae, bacterial-derived polymers are often $\mathrm{O}$-acetylated at $\mathrm{O}-2$ and/or O-3 of D-mannuronate, which is catalysed by mannuronate acetylase [15, 16] (Fig. 1A). Acetylation can affect the ion-binding selectivity [17] and water-binding properties of polysaccharides [18].

Alginate consists of $\beta$-D mannuronic acid $(\mathrm{M})$ and its C-5-epimers $\alpha$-L guluronic acid (G) by 1,4-linked glycosidic bond. Alginate consists of 1,4-linked C-5-epimers

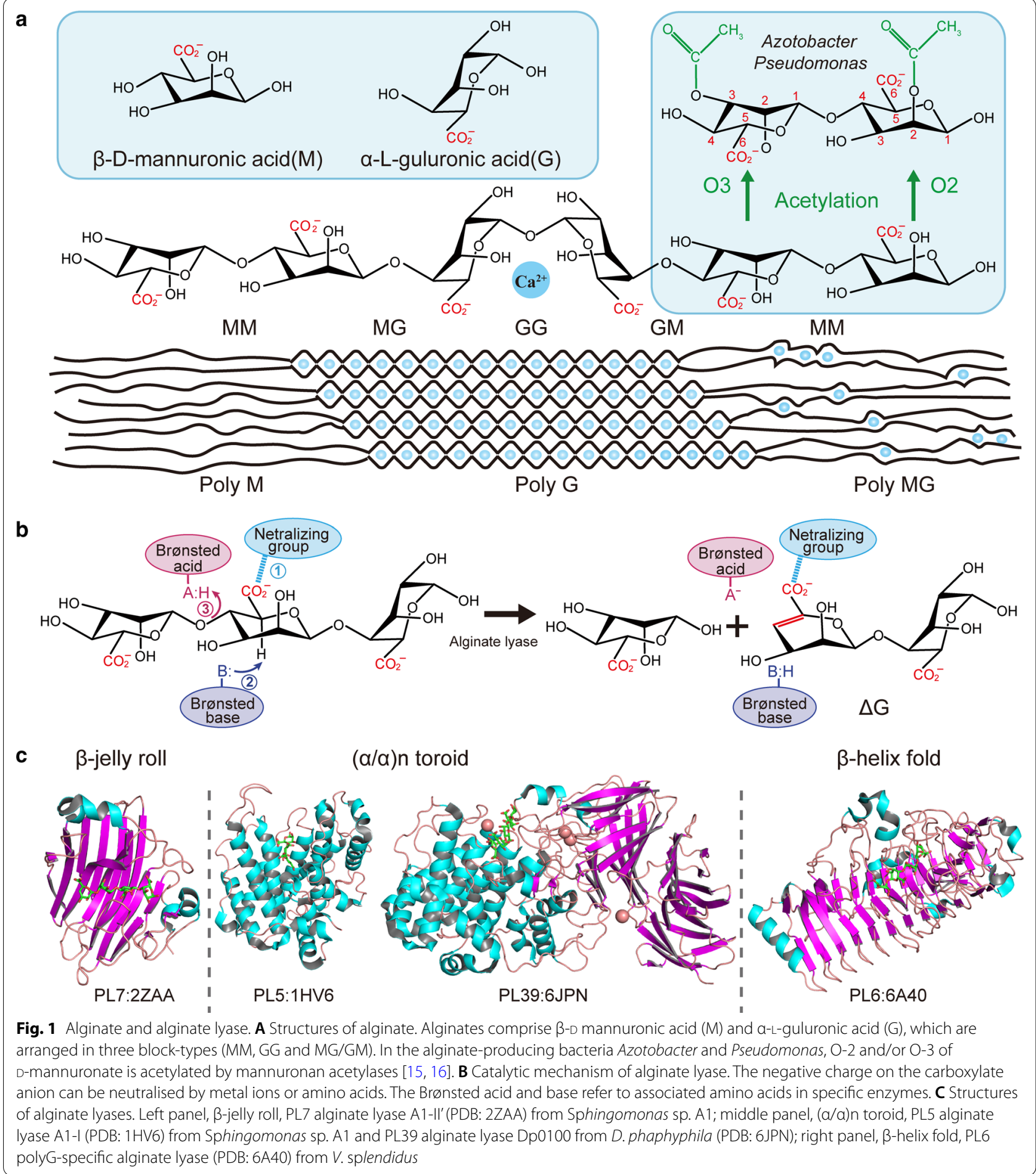


$\beta$-D mannuronic acid (M) and $\alpha$-L-guluronic acid (G). Both $\mathrm{M}$ and $\mathrm{G}$ are arranged in at least one of three block types: homopolymeric M-residues (Poly M), homopolymeric G-residues (Poly G), and randomly alternating M- and G-residues (Poly MG; Fig. 1A). The block types and alginate sizes influence the gel formation ability and viscosity of polysaccharides [19]. Due to the variable three-dimensional structures of monomers, the arrangements of the monomeric units are also an important factor affecting the properties of alginates [19]. Moreover, G blocks can form a "buckled" chain conformation and chelate divalent metal ions (Fig. 1A). This structure allows the synthesis of strong but brittle gels, hence the flexibility of polysaccharides is reported to decrease with increasing G content [20].

\section{Alginate lyases}

Alginate lyases are a group of enzymes that catalyse the degradation of alginate via $\beta$-elimination of glycosidic bonds. They produce various oligosaccharides with unsaturated uronic acid at the non-reducing end, or 4,5-unsaturated uronic acid monomers mannuronate $(\triangle \mathrm{ManUA})$ and guluronate $(\triangle \mathrm{GulUA})$. Alginate lyases are present in various organisms including marine algae, marine molluscs, fungi, viruses, and a huge number of terrestrial and marine bacteria, of which bacteria are the major producers. Some alginate-producing bacteria, such as Pseudomonas aeruginosa and Azotobacter, are also capable of expressing alginate lyases even though they cannot use alginate as a carbon source [21].

\section{Classification of alginate lyases}

Alginate lyases are categorised into 12 families of polysaccharide lyases in the CAZy database (www.cazy. org): PL5, PL6, PL7, PL14, PL15, PL17, PL18, and the recently identified families PL31, PL32, PL34, PL36 and PL39 [22-24] (Additional file 1: Table S1). Among them, the PL14 family is the mostly widespread and contains alginate lyases from eukaryotes [25-28], bacteria and viruses [29]. Based on their cleavage specificity (i.e. acting on M-rich or G-rich alginates), alginate lyases are classified as M-specific lyases (polyM lyase, EC 4.2.2.3), G-specific lyases (polyG lyase, EC 4.2.2.11), or bifunctional MG lyases (polyMG lyase, EC 4.2.2.-). For example, PL5 family members belong to M-specific lyases, while PL7 family lyases possess different substrate specificities and are able to degrade all types of alginates [30]. Based on their mode of action, all reported members of PL5, PL18, PL31, PL36, and PL39 are endolyases (Additional file 1: Table S1). Among PL7 alginate lyases, most reported PL7 alginate lyases are endolytic except for two members which are exolyases: AlyA5 from Zobellia galactanivorans $\mathrm{Dsij}^{\mathrm{T}}$ [31] and VxAly7D from Vibrio xiamenensis QY104 [32]. PL14 members are also mostly endolyases except for vAL-1 from Chlorellar virus CVN1 which exhibited endo- and exo-activity [29] and HdAlex from abalone, Haliotis discus hannai which was exolytic [26]. Exolyases are mainly found in oligo-alginate lyase families PL15 and PL17. Among PL15 alginate lyases, A1-IV from Sphingomonas sp. A1 was the first reported exo-type enzyme to be characterised [33, 34]. Notably, PL17 family members Alg17B from BP-2 [35] and AlgL from Sphingomonas sp. MJ3 [36] were shown to be endoand exo-lytic. The modes of action are listed in Additional file 1: Table S1.

Notably, when heterologously expressed, family PL7 Sphingomonas sp. A1 alginate lyase A1-II' displayed broad substrate specificity [37]. However, no expression of A1-II' was observed in cells, even in the presence of alginate, indicating that A1-II' may be not involved in Sphingomonas sp. A1 alginate metabolism in vivo. Consistent with this, PL7 Vibrio alginolyticus alginate lyase Aly1 was identified with broad activity on different substrates. However, aly1 transcript levels were low and not regulated by alginate. This expression pattern is different from other alginate-degrading genes that are upregulated by alginate (Zhang and $\mathrm{Li}$, unpublished data). Furthermore, deletion of aly1 did not affect growth or alginate-degrading activity, which further implied that aly1 may provide only a minor contribution to alginate utilisation in $V$. alginolyticus (Zhang and $\mathrm{Li}$, unpublished data). Recently, AusR, the regulator responsible for alginate catabolism in the marine flavobacterium $Z$. galactanivorans $\mathrm{Dsij}^{\mathrm{T}}$, was the first such regulator to be identified [38]. AusR belongs to the GntR family, and can repress the expression of most alginate-utilising genes except for the alginate lyase gene alyA7. AlyA7 is proposed to act as a "sentry" enzyme and it is expressed at a basal level even in the absence of alginate. Upon addition of alginate, AlyA7 can release the first oligosaccharide effectors, which can prevent AusR from binding to its targets, thereby triggering a rapid expression of the whole alginate-degrading system [38]. In line with this, $V$. alginolyticus Aly1 plays a similar role in alginate catabolism (Zhang and $\mathrm{Li}$, unpublished data). Thus, it is reasonable to hypothesise that Sphingomonas sp. A1 alginate lyase A1-II' may also be involved in the initial degradation of the polymer.

\section{Domain organisation of alginate lyases}

Besides the catalytic domain, a number of alginate lyases contain auxiliary domains. Carbohydrate-binding modules (CBMs) are the most common auxiliary domain, and they play a key role in alginate degradation. For example, CBM13 in AlyL2 from Agarivorans sp. L11 can elevate enzymatic activity and thermostability [39], similar 
to CBM32 and CMB9 of TsAly7B from Thalassomonas sp. LD5 [40]. In agreement with this, truncation of Aly5 non-catalytic regions from Flammeovirga sp. strain MY04 not only decreases enzymatic activity and stability, but also causes the accumulation of larger oligomer products, indicating a pivotal role for CBMs in enzyme binding and decomposition of small substrates [41]. AlgH from Marinimicrobium sp. H1 [42] and AlyM from Microbulbifer sp. CGMCC 14061 [43] exhibit a completely different trait and display higher reactivity and thermal stability following loss of their CBM32 domain. However, the CBM32 domain of AlyQ from Persicobacter sp. CCB-QB2 was not involved in the activity of alginate lyase under the tested conditions, but capable of binding to cleaved alginate, which played an important role in the recognition of alginate termini [44]. Because only minimal data are available for the functions of CBMs, their detailed functions and mechanisms related to alginate cleavage and recognition remain unclear. In addition to CBMs, alginate lyases containing tandem catalytic domains that are ubiquitous in many alginate-degrading bacteria $[45,46]$. However, the role of individual catalytic domains and their interactions remain unknown.

\section{Structure of alginate lyases}

Except for PL32, PL34 and PL36, the three-dimensional structures of alginate lyases from various families have been determined, and classified into three types: $\beta$-jelly roll (PL7, PL14 and PL18), $(\alpha / \alpha) n$ toroid (PL5, PL15, PL17 and PL39), and $\beta$-helix fold (PL6 and PL31; Fig. 1C). The $\beta$-jelly roll is the most prevalent fold and consists of a pair of antiparallel $\beta$-sheets curved nearly $90^{\circ}$ in the middle. The inner concave $\beta$-strands together with the surrounding loops form a globular or tunnel-shaped core that is particularly important for alginate binding and degradation. Despite sharing a common fold, significant differences are also observed among enzymes with different modes of action, which have been well summarised [47]. Recently, the structure of the novel PL7 alginate lyase AlyC3 from Psychromonas sp. C-3 was solved [48]. In this dimeric endo-alginate lyase, dimerisation is an adaptation to seawater salinity.

The $(\alpha / \alpha) n$ toroid fold is a barrel-like architecture consisting of several antiparallel $\alpha$-helices (Fig. 1C, middle panel). The catalytic cavity includes two outer and inner $\alpha$-helices layers, and forms a tunnel-like groove. Except for two PL5 folds containing one single $(\alpha / \alpha) 6$ toroid catalytic domain [49], alginate lyases from PL15, PL17 and PL39 are multi-domain enzymes, and structures include one or more additional domains [24, 50, 51]. Notably, although the catalytic groove of the PL39 alginate lyase Dp0100 from the marine thermophile Defluviitalea phaphyphila resembles that in exolytic lyases of
PL15 and PL17 families, analyses of both oligosaccharide product and complex structures with a pentasaccharide suggest that $\mathrm{Dp} 0100$ serves as an endolytic alginate lyase [24] (Fig. 1C, middle panel).

The right-handed $\beta$-helix class displays two different dimer and monomer catalytic modes. The PL6 alginate lyase AlyGC from Paraglaciecola chathamensis S18K6T functions as an exolytic and polyG-specific enzyme [52]. It forms a homodimer and each monomer contains a catalytic $\mathrm{N}$-terminal and a $\mathrm{C}$-terminal domain essential for dimerisation and alginate degradation. The conformation of AlyGC is altered when a substrate is bound, thereby leading to only one substrate binding to one active centre [52]. The other three alginate lyases for which structures have been reported, two from PL6 (BcelPL6 from Bacteroides cellulosilyticus DSM 14838 [53] and AlyF from Vibrio splendidus [54]) and one from PL31 (PsAly from Paenibacillus sp. FPU-7 [22]), are endolytic monomeric $\beta$-helices, and each harbours one catalytic domain. These alginate lyases catalyse $\mathrm{Ca}^{2+}$-assisted $\beta$-elimination to degrade substrates, except for the $\mathrm{Ca}^{2+}$-independent alginate lyase AlyF [54].

\section{Catalytic mechanism and sequence characteristics in the active site architecture of alginate lyases}

Although the cleavage mechanisms of alginate lyases have not been fully revealed, a stepwise catalytic process has been suggested [55]. First, the negative charge on the carboxylate anion is quenched via neutralisation by a salt bridge. Next, the proton on C-5 is abstracted by a general based-catalysed reaction, and an enolate intermediate is generated. Finally, electrons are transferred from the carboxyl group, forming a double bond between C-4 and $\mathrm{C}-5$, resulting in the $\beta$-elimination of the 4-O-glycosidic bond (Fig. 1B). However, alginate lyases belonging to different PL families display different sequence profile characteristics in the active site architecture. For example, in PL5 alginate lyases, which are all M-specific, the conserved catalytic centre sites include asparagine $(\mathrm{N})$, histidine $(\mathrm{H})$ and tyrosine $(\mathrm{Y})$ residues. PL5 A1-III was the first alginate lyases for which the catalytic mechanism was determined, and its catalytic site residue Y246 was proposed to function as both the catalytic base and the acid $[49,56]$. Moreover, the sequence profile showed that many other amino acid residues at -3 to +1 subsites are also highly conserved, including Arg312, Arg342, Tyr249, Trp141, Asn190 and Arg239 in A1-III (PDB ID: 4F13, template structure; Fig. 2A). Consistent with these A1-III residues [49], our sequence profiling revealed that Arg312 and Arg342 form hydrogen bonds with sugar residues of M-2 O-62 and M-1 O-62, respectively, and $\mathrm{CH}-\pi$ interactions are observed between Tyr249, Trp141 and M-1 (Fig. 2A). In addition, conserved N190 may form 


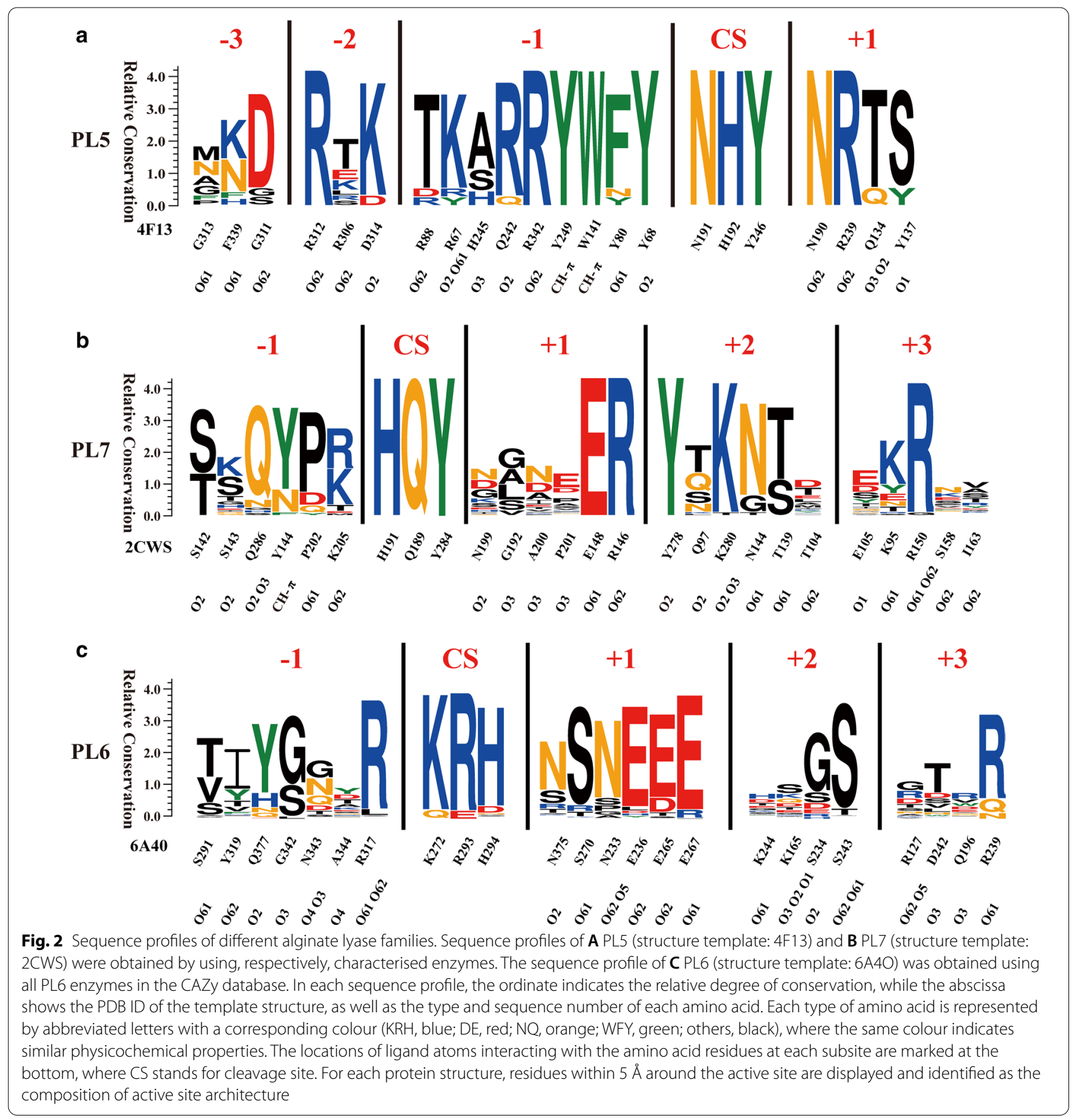

hydrogen bonds with $M+1$, while Arg239 likely stabilises the negative charge of ionised Y246 [49]. Furthermore, based on our early studies on xylanases [57, 58], variable amino acid residues at the -3 subsite of the active site architecture might provide a clue to alginate lyase engineering for potential industrial applications.

Sequence profiles of PL7 alginate lyases showed that conserved residues His, Gln and Tyr form the catalytic centre sites, as first demonstrated for A1-II' (Fig. 2B,
AI-II, PDB ID: 2CWS used as template structure) [59]. Among them, His and Tyr may act as the Brønsted base and the Brønsted acid of the reaction, respectively [48]. Meanwhile, some conserved amino acid residues around the catalytic centre sites were observed, including Glu148, Arg146, Lys280, Tyr278 and Arg150, all candidates for the formation of hydrogen bonds with substrates in A1-II' (Fig. 2B). In addition, two sets of $\mathrm{CH}-\pi$ interactions were suggested between Tyr284 
and Arg146, and between Tyr278 and Arg150 in A1-II' [59]. Recently, the catalytic process of PL7 alginate lyase AlyC3 was proposed to be similar to that of A1-II'. In addition, conserved residues Arg78 and Gln125 of AlyC3 (corresponding to Arg146 and Gln189 of A1-II') probably neutralise the negative charge of the carboxylic group at the +1 subsite, while conserved residues Gln246 and Arg82 (corresponding to Gln286 and Arg150 of A1-II') are likely involved in substrate binding [48]. However, distinct from other PL7 alginate lyases [59-61], AlyC3 does not require the opening of a loop to bind the substrate [48].

In PL6 alginate lyases, residues in the centre of the active sites are mainly Lys, Arg and His (Fig. 2C, AlyF, PDB ID: 6A40 as template structure). Lys and Arg are suggested to function as the catalytic base and the catalytic acid, respectively [52]. In addition, some conserved residues at -1 to +3 subsites also play important roles in alginate degradation, such as Arg317, Asn233, Glu236, Glu265, Glu267 and Arg239 [52-54]. Among them, Asn233, Glu236, Glu265 and Glu267 are required for polar interactions between the substrate and the alginate lyase enzyme. Polar interactions are mediated by $\mathrm{Ca}^{2+}$ in AlyGC [52] and BcelPL6 [53] but by water in AlgF [54]. $\mathrm{Ca}^{2+}$ may neutralise the carboxyl group of an alginate residue at the +1 subsite, similar with the role of Arg in PL5 and PL7. Consistent with this, no positively charged residue is observed at the +1 subsite in PL6 alginate lyases (Fig. 2). Notably, unlike the amino acid residues in the centre of the active sites of PL5 and PL7, which are completely conserved, Lys and His are not observed in all members of PL6, and the absence mainly occurs in the subfamily 3 (Additional file 1: Fig. S1). Further analyses revealed that the catalytic site architecture of superfamily 3 is completely different from that of subfamilies 1 and 2 (Additional file 1: Fig. S1). However, because no PL6 alginate lyase belonging to subfamily 3 has been characterised, the function and active site of PL6-3 remain unknown. Therefore, this distinct catalytic site architecture, which is constructed using enzymes of subfamilies 1 and 2, raises a question whether it is appropriate to classify subfamily 3 into the PL6 family. A more extensive investigation is required to gain insight into the classification and catalytic mechanism of PL6 subfamily 3.

As shown in Additional file 1: Fig. S2, active centre sites of PL15, PL17, PL36, and PL39 families are not completely conserved because only one crystal structure of enzyme in complex with a small oligosaccharide substrate was solved in each family. In PL15 family, His311, Tyr365, and His531 form the catalytic centre sites, and His311 and Tyr365 serve as the catalytic base and acid, respectively [50]. In PL17 family, Tyr258 and Tyr450 are proposed to function as the general acid and base, respectively [51]. However, because residue Tyr450 is not conserved among PL17 members, we cannot exclude that His202 may act as the general base in PL17 members which do not contain Tyr450 in the catalytic centre sites (Additional file 1: Fig. S2). Therefore, more crystal structures of PL17 enzymes are required to fully illustrate the active site residues in catalysis. In PL36 family, residues in the centre of the active sites are conserved, including Tyr185, Arg169, Tyr187, and Lys143 (Additional file 1: Fig. S2). Among them, Lys143 may serve as both the general acid and base, and Tyr185 may play a role in proton transfer [62]. In PL39 alginate lyases, the conserved catalytic centre sites include Tyr239, His405, Asp186, and His187 (Additional file 1: Fig. S2). Tyr239 and His405 likely function as the catalytic acid and base, respectively [24]. In addition, some conserved residues at -2 to +3 subsites might also play an important role in alginate degradation. For example, residues Gly340, Tyr135, Ile134, Glu235, Asn404, Arg183 and His185 are probably used for substrate binding (Additional file 1: Fig. S2). Furthermore, more biochemical analyses of alginate lyases and crystal structures of enzymes in complex with ligand are required to fully understand the catalytic mechanism of different alginate lyase families.

\section{Alginate degradation pathways in vivo Three systems for alginate assimilation}

As mentioned above, knowledge of the functions of alginate lyases has increased dramatically in recent years. However, we have only begun to probe the biological process of alginate decomposition using genetic techniques and omics approaches. To date, three different strategies have been reported for alginate-utilising bacteria: the polysaccharide utilisation loci (PUL) system, the "scattered" system, and the "pit" transport system (Fig. 3). The PUL and scattered systems are defined based on the localisation of alginate degradation-associated genes. Our bioinformatics analysis revealed that the PUL system is common and present in a variety of alginate-utilising bacteria, while the scattered system mainly occurs in Vibrio strains. The pit transport system is limited to Alphaproteobacteria strain Sphingomonas sp. A1 [63] and its relatives (Fig. 4A).

\section{The PUL system}

PULs are loci related to polysaccharide utilisation, which were first described by Bjursell et al. [64]. PULs comprise co-regulated genes encoding various substratespecific carbohydrate-active enzymes, substrate-binding proteins, oligosaccharide transporters, glycan-specific TonB-dependent receptors (SusC proteins), SusD-like substrate-binding proteins (SusD-like), regulators, and hypothetical proteins. First, outer membrane alginate 


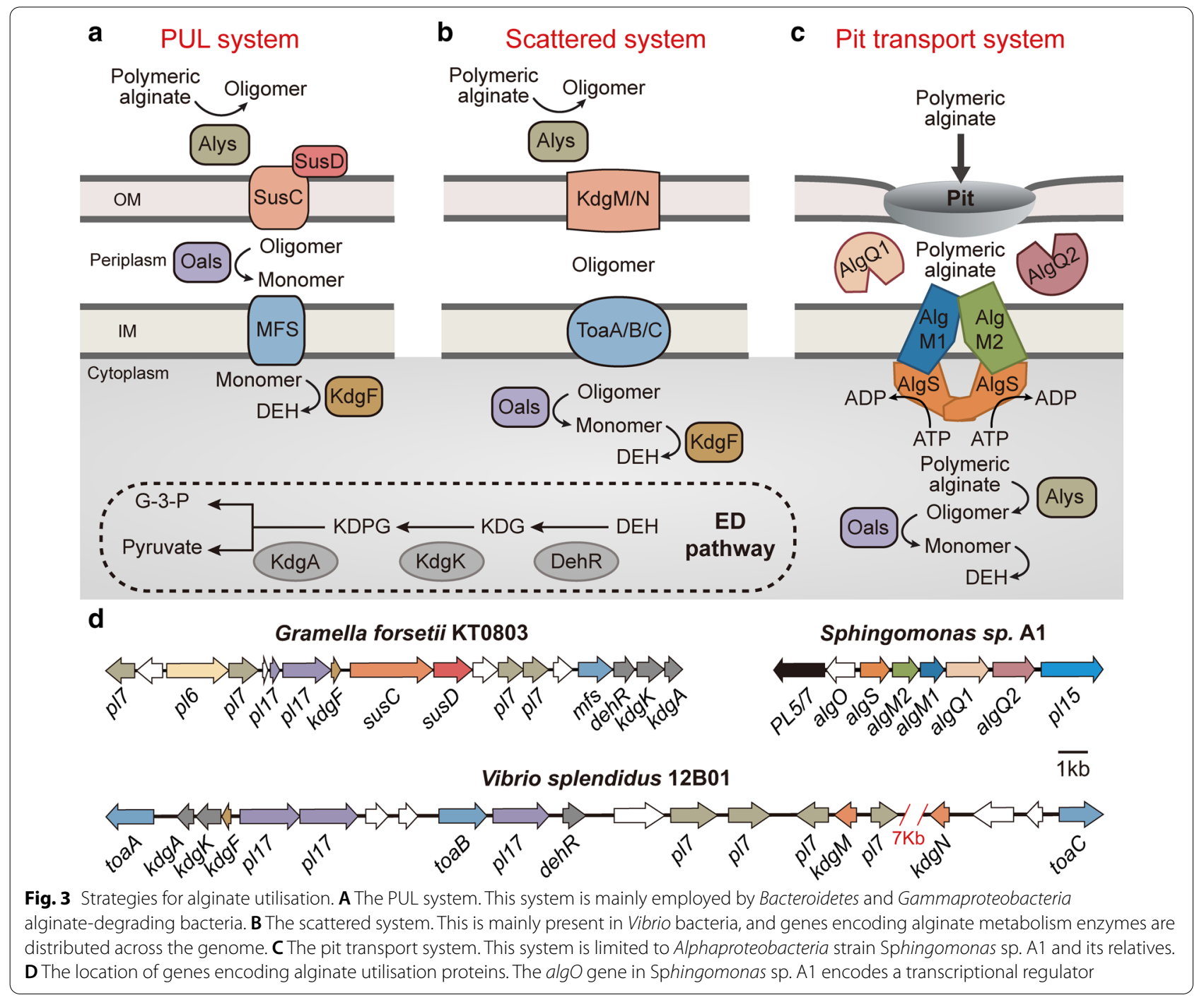

lyases catalyse high molecular weight carbohydrates into oligomers. Once transported into the periplasm by SusC/ SusD-like, these oligosaccharide products are converted into monomers by periplasmic alginate lyases. Finally, monomers are delivered into the cytoplasm via major facilitator superfamily (MFS) transporter, and $\mathrm{KdgF}$ catalyses the ketonisation of unsaturated monomers into 4-deoxy-L-erythro-5-hexoseulose uronate (DEH) [65]. $\mathrm{DEH}$ is stepwise degraded into 2-keto-3-dexy-gluconate (KDG), keto-deoxy-phospho-gluconate (KDPG), glyceraldehyde triphosphate (G-3-P) and pyruvate (Fig. 3A). The occurrence of the susC/susD-like pair is a hallmark for detection of PULs [66, 67]. Conformational changes of the SusC/SusD-like complex facilitate transport of oligomer products into cells [68]. Moreover, this transporter is not merely restricted to alginate utilisation, but also other major carbohydrates of macroalgae and plants such as mannitol, laminarin, starch and xyloglucan [69].

\section{The scattered system}

The scattered system comprises genes related to alginate decomposition not co-localised in the same operon, but distributed across different regions of the whole genome. In this system, the alginate-cleaving process is also initiated by extracellular or membrane-attached polysaccharide lyases, which act on the polysaccharide backbone to produce oligomers [70]. After being transported into the cell by outer membrane porin KdgMN and inner membrane symporter ToaABC, these products can be stepwise degraded to 4,5-unsaturated mannuronate or guluronates by specific oligosaccharide lyases [7, 71] (Fig. 3B). Therefore, unlike the PUL system, the scattered system lacks homologs of TonB-dependent receptors and MFS transporters, indicating a different way to import alginate oligomers. Instead, the scattered system employs porin $\mathrm{KdgMN}$ for extracellular substrate transport, while 
(See figure on next page.)

Fig. 4 Distribution and abundance of alginate lyases in alginate-utilising microorganisms. A Phylogenetic tree of alginate-utilising bacteria with the distribution and abundance of alginate lyases and transporters. In the CAZy database there are $\sim 250$ species with genome sequence information, and 46 representatives were used to construct the tree based on alignment of 165 rRNA gene sequences. Poly-and oligo-alginate lyases are listed separately and shown as Alys and Oals, respectively. In addition, outer and inner membrane transporters for substrate delivery were analysed and are shown as OMP and IMP, respectively. MFS, major facilitator superfamily; ABC, ATP-binding cassette transporter. B Composition of SusC and SusC-like. SusC mainly occurs in Bacteroidetes and contains three putative domains: a carboxypeptidase regulatory-like domain (CRLD), a plug domain (an independently folded subunit of the TonB-dependent receptor that acts as a channel gate and blocks the pore when the channel is bound by a carbohydrate substrate), and a TonB-dependent receptor domain (TBDR). SusC-like present in Gammaproteobacteria lacks an N-terminal CRLD domain

it is unclear whether a substrate receptor occurs in this system.

\section{The pit transport system}

The pit transport system is a completely distinct strategy for alginate decomposition. During alginate assimilation, no extracellular degradation occurs, and alternatively, alginate macromolecules are directly incorporated into the cytoplasm through a pit transport system [33, 63] (Fig. 3C). This system comprises a superchannel on the cell surface, periplasmic binding proteins, and a cytoplasmic membrane-bound ATP-binding cassette (ABC) transporter. When alginate is present, outer membrane alginate-binding proteins, such as flagellin homologs, are responsible for alginate recognition and superchannel formation [72]. Once it enters the cell, alginate is bound to periplasmic binding proteins and delivered to an inner membrane-bound ABC transporter. Finally, cytoplasmic alginate lyases cleave the transferred substrate into monomers. Overall, the most significant differences among the three systems are their distinct recognition and transport components.

\section{Bacteria with different systems}

Bacteroidetes are microorganisms that employ the PUL system to degrade various polysaccharides [67, 73, 74]. They are ubiquitous in the marine realm and serve as the major contributor to the consumption of complex organic substrates. Generally, Bacteroidetes strains capable of alginate uptake harbour one or more PULs. It was first experimentally verified in Z. galactanivorans, which harbours two alginate-specific PULs, and both regulons are modulated by alginate $[75,76]$. The regulator AusR is responsible for alginate catabolism by repressing the expression of most PUL genes in the absence of alginate [38]. Using quantitative proteomics combined with isotope labelling and subcellular protein fractionation, Kabisch et al. delineated the complete pathway of alginate utilisation in the marine Bacteroidetes strain Gramella forsetii KT0803 (Fig. 3A, D) [73]. A similar process of alginate degradation is also proposed in other Bacteroidetes, such as Flavobacterium sp. strain UMI-01 [77] and

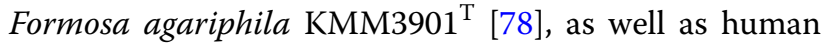
gut bacterium Bacteroidetes intestinalis DSM 17393 [79].

Populations of Proteobacteria specialised for successive alginate degradation mainly belong to Gammaproteobacteria, and two different strategies have been found (Fig. 4A). One is the PUL-like system resembling that in Bacteroidetes, and the other is the scattered system mainly present in Vibrio species. Alteromonas macleodii, one of the most important contributors to algal degradation in diverse marine systems [80-83], is a representative of the PUL-like system. It has been shown that $A$. macleodii can account for more than $60 \%$ of the bacterial community in an alginate-supplemented microcosm [84], and genomic and metabolic variability occurs in different $A$. macleodii strains [85]. Among these strains, $A$. macleodii 83-1 isolated from an alginate-rich microcosm is usually used as a model strain due to its capability to degrade various algal substrates [83]. However, unlike the "classical" PUL system in Bacteroidetes, no susD-like gene is found in Gammaproteobacteria, and SusC homologs lack an N-terminal domain (carboxypeptidase regulatory-like domain, $\sim 70$ amino acids, Fig. $4 \mathrm{~B}$ ).

The scattered system is mainly present in Vibrio species. Nevertheless, in Vibrio species such as $V$. splendidus [7], most genes responsible for alginate utilisation are clustered in different directions, and are proposed be derived from Flavobacteriia [75]. In addition to gene localisation, the lack of homologs of TonB-dependent receptors and MFS transporters indicate that Vibrio strains adopt a different method to import alginate oligomers, possibly using outer membrane porin $\mathrm{KdgMN}$ and inner membrane symporter ToaABC for oligomer import. Notably, although most oligo-alginate lyases (PL15 and PL17 members) are capable of producing monomers in vitro, the conversion of oligomers to monomers in vivo appears to be accomplished by different oligo-alginate lyases synergistically. For example, although all three oligo-alginate lyases (OalA, OalB and $\mathrm{OalC}$ ) in $V$. splendidus strain $12 \mathrm{~B} 01$ are able to produce monomers in vitro [71], their effects on alginate-dependent growth in vivo are completely different, with no growth when oalB is absent, delayed growth when oalC 


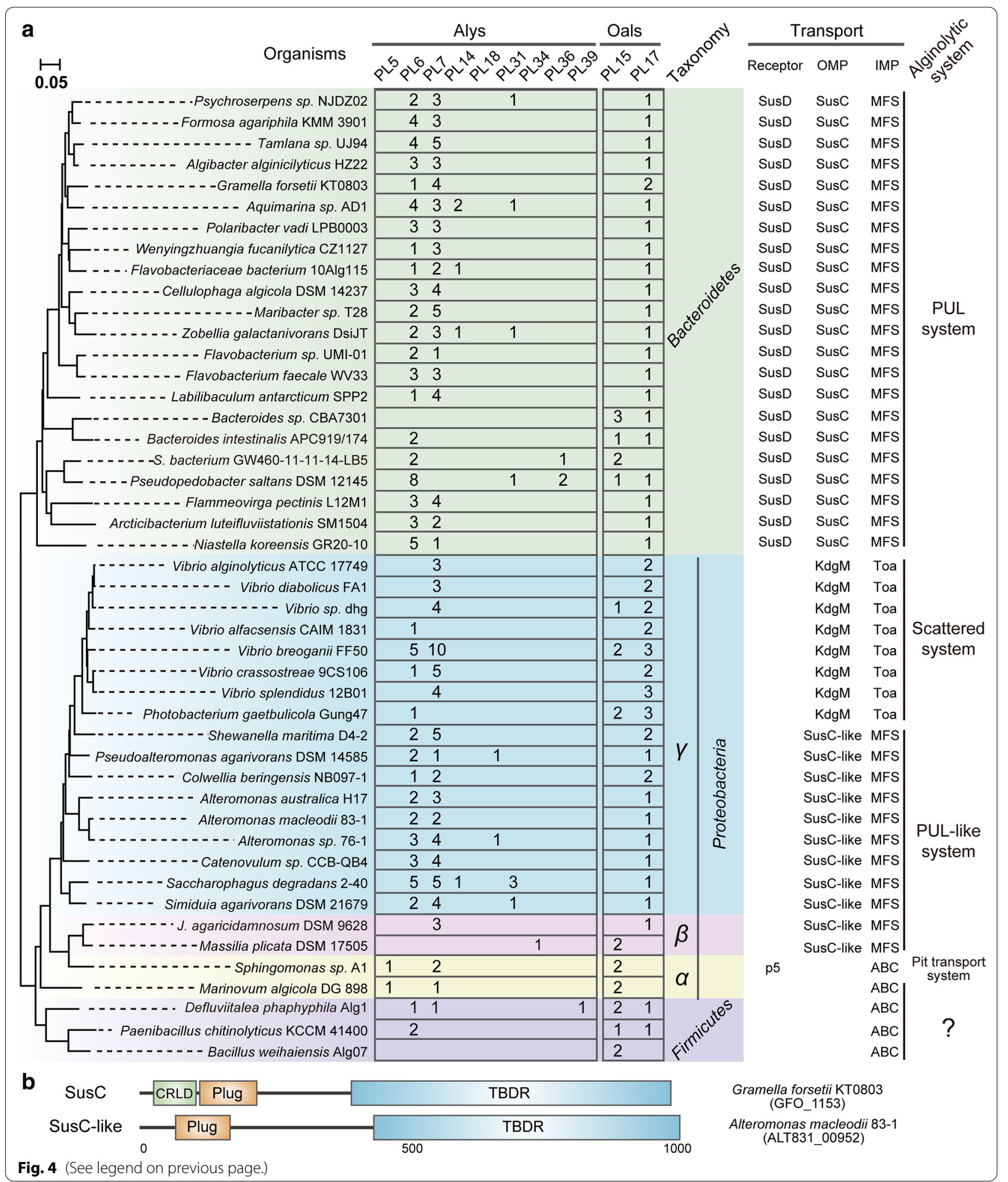

is lacking, and wild type (WT)-like growth without oalA [7]. Thus, the production of monomers from oligomers is probably achieved by synergy between different oligo-alginate lyases, and similar results were observed in $V$. alginolyticus (Zhang and Li, unpublished data). 
The pit transport system appears to be limited to Alphaproteobacteria strain Sphingomonas sp. A1 and its relatives. Unlike the PUL and scatter systems, strain A1 imports alginate into the periplasm without prior depolymerisation. The outer membrane protein P5, homologous to bacterial flagellin, acts as a receptor for alginate transport [72]. Moreover, the function of flagellin P5 binding to alginate is proposed to be a universal property of flagellins since the Escherichia coli flagellin $\mathrm{FliC}$ is also capable of alginate interaction in vitro [72]. In addition to $\mathrm{P} 5$, another surface protein (Algp7) is involved in alginate binding [86]. Algp7 is homologous to lipoproteins, but lacks a lipid moiety. Instead, it harbours a metallopeptidase motif, and has a domain homologous to the M75 peptidase motif-containing protein $\mathrm{EfeO}$, a component of a ferrous ion transporter [87]. Algp7 has an affinity for metal ions, hence it may deprive alginate/metal complexes of metal ions [88]. When alginate enters the cell, it is bound by the periplasmic solute-binding proteins $\mathrm{AlgQ} 1$ or $\mathrm{AlgQ} 2$, and transferred to the $\mathrm{ABC}$ transporter AlgM1M2SS, a heterotetramer of AlgM1, AlgM2 and AlgS [89-91]) (Fig. 3C, D). An overview of the pit transport system has been intensively reviewed recently [63].

Besides Bacteroidetes and Proteobacteria, several microorganisms belonging to Firmicutes are also capable of alginate metabolism. For example, the thermophilic marine strain $D$. phaphyphila harbours a complete pathway for alginate utilisation, and can directly convert alginate to ethanol $[92,93]$. In addition, an alginolytic pathway is also suggested in the marine strain Bacillus weihaiensis [94]. During algal decomposition, B. weihaiensis exhibits enzymatic activity toward alginate and laminarin substrates. However, the prioritisation of alginate over laminarin is different from that in A. macleodii 83-1, with initial laminarin consumption followed by simultaneous alginate and pectin degradation [94, 95]. The difference probably results from different ecological niches. Bioinformatic analysis reveals that these Firmicutes bacteria contain scattered genes for alginate degradation (similar to the scatter system), but use an $A B C$ transporter for oligomer uptake, similar to the pit transport system (Fig. 4A). Further genetic investigation is required to fully establish the alginate metabolic pathway in Firmicutes.

\section{Different ecophysiological types of alginate utilisation}

Within strains of the common marine Vibrionaceae bacteria, a huge diversity of alginate-decomposing enzymes have been identified, and many of these strains are associated with animals [96]. Vibrionaceae species cooccurring in the same environmental samples display differences in alginate degradation pathways [97]. This differentiation may result from horizontal gene transfer, leading to adaptive radiation, thereby mitigating competitive exclusion and fine-scale resource partitioning of alginate [97]. On this basis, Hehemann et al. defined three different ecophysiological types for alginate utilisation: pioneer, scavenger, and harvest [97]. Pioneers possess extracellular polysaccharide and oligosaccharide lyases, and are able to secrete alginate lyases that cleave insoluble alginate polymers into soluble polymers and oligomers. These products are subsequently utilised by harvest and scavenger classes. Scavengers that only contain oligosaccharide lyases cannot decompose alginate directly, but can utilise oligomers. In contrast, harvest organisms are selfish and have membrane-anchored poly- and oligoalginate lyases, and can therefore both degrade polymers and use oligomers produced by pioneers [97]. The scattered system in Vibrio strains may be more beneficial for adapting to different niches, resulting in different ecophysiological types supporting coexistence.

Different strategies for alginate degradation are also observed in microorganisms belonging to different phyla. For example, a biogeographical study of bacterial polysaccharide degradation in the Atlantic Ocean revealed that pioneers and scavengers predominantly belong to the Alteromonadaceae and SAR11 clades, respectively, while harvest strains mainly belong to Bacteroidetes, Gammaproteobacteria and Planctomycetes [98]. Consistent with this, marine Bacteroidetes member G. forsetii functions as a harvest strain, similar to members of gut Bacteroidetes [99]. However, in California coastal seawater, Alteromonadaceae A. macleodii strain 83-1 appears to be selfish since it cannot benefit non-alginolytic microorganisms by cross-feeding on alginate degradation or other metabolic products when alginate particles are supplied [100]. Therefore, bacterial hierarchy for polysaccharide utilisation may be largely dependent on bacterial community composition and environmental factors, such as polysaccharide types.

\section{Applications and prospects of alginate lyases and associated metabolic pathways} Alginate lyases for alginate oligosaccharide preparation Alginate oligosaccharides (AOS) possess attractive biological properties, especially versatility and beneficial effects on human health. Their bioactivities have been summarised comprehensively by Liu et al. including prebiotic, antitumor, antihypertensive, anti-diabetic, antimicrobial, antioxidant, anticoagulant, and immunomodulatory activities [3]. Traditional methods for AOS production require strong acid and alkaline [101], which may cause environmental pollution. In contrast, enzymatic methods are more environmentally friendly. However, except for one commercialised alginate lyase (CAS number: 9024-15-1, Sigma-Aldrich), most alginolytic 


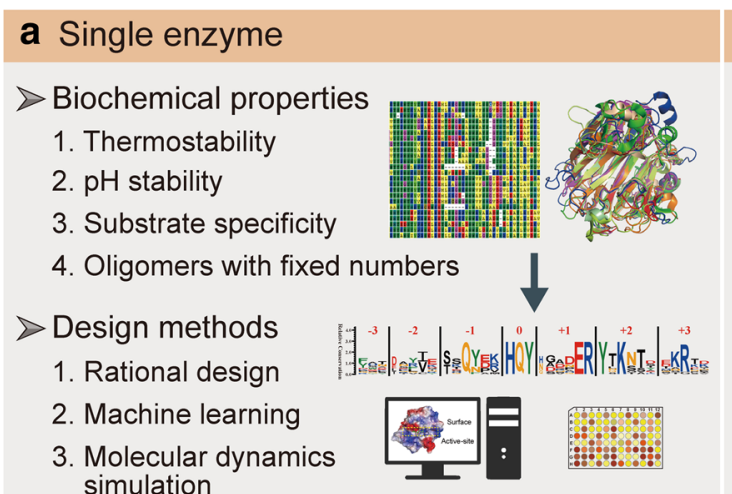

Alginolytic pathways

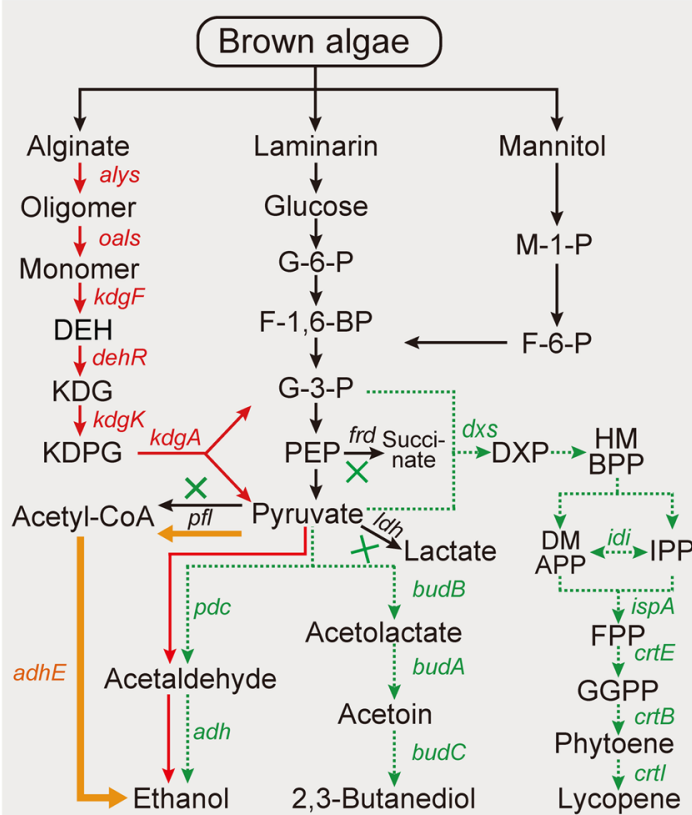

\section{b Combined enzymes}

\section{Alys combined with Oals}

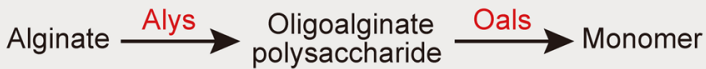

2. Alginate lyase combined with other enzymes

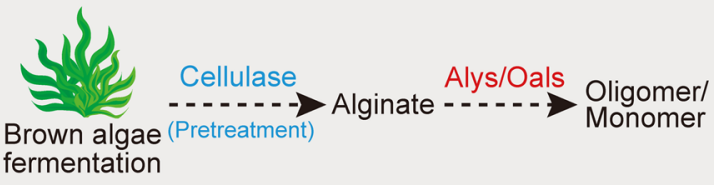

Industrial microbes

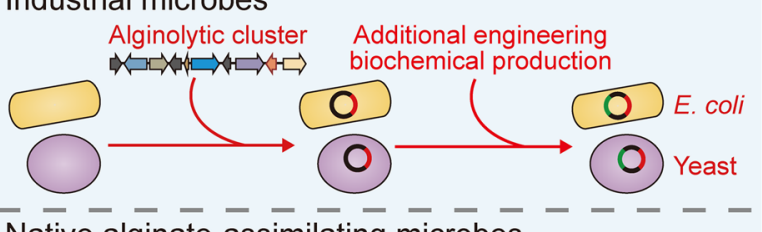

Native alginate-assimilating microbes

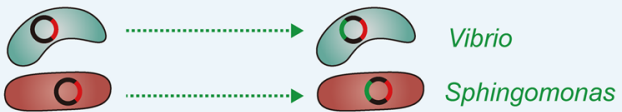

Defluviitalea

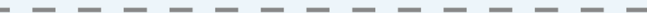

Recombined microbial consortium

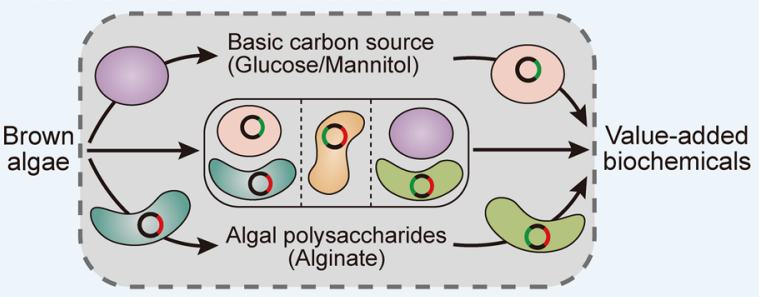

Fig. 5 Application of alginate lyases and associated metabolic pathways. The schematic diagram shows the application of single (A) and combined (B) enzymes. C Schematic pathways for the production of bioethanol and other value-added biochemicals. A workflow for ethanol production in industrial microbes (E. coli and S. cerevisiae) is shown as red solid arrows. In S. cerevisiae, the eukaryotic DEH transporter DHT1 is introduced for DEH entry. The workflow for bioethanol production in native alginate-utilising bacteria Sphingomonas sp. A1 and Vibrio sp. dhg is shown as green dashed arrows. Besides ethanol production, Vibrio sp. dhg was also engineered to synthesise 2,3-butanediol and lycopene. Alginate-utilising strain D. phaphyphila harbours a distinct pathway and stepwise converts pyruvate into acetyl-CoA and ethanol, which is shown as orange solid arrows. In E. coli and Vibrio sp. dhg, endogenous genes including frd encoding fumarate reductase, Idh encoding lactate dehydrogenase, and pfl encoding pyruvate-formate lyase, were deleted to block by-product synthesis, shown as green crosses. In Sphingomonas sp. A1, only lactate formation is inhibited by deletion of Idh gene

enzymes have been studied at the laboratory level, and show great potential at high $\mathrm{pH}$ and impressive heat stability (Fig. 5A). For example, alginate lyase AMOR_PL7A from a hot vent in the Arctic Mid-Ocean ridge displayed stable polyM-specific endolytic activity over a wide temperature range $\left(60-80{ }^{\circ} \mathrm{C}\right), \mathrm{pH}(4.7-7.8)$ and salinity $(0-2 \mathrm{M})$ [102]. Alginate lyase NitAly from marine strain Nitratiruptor sp. SB155-2 exhibits highest activity at $70{ }^{\circ} \mathrm{C}$ [103], while PL36 family alginate lyase Aly36B from Chitiophaga sp. MD30 [62] and Aly08 from Vibrio sp. SY01 [104] are alkaline-stable, with optimal pH values of 9.0 and 8.35 , respectively. In addition to enzymes with high $\mathrm{pH}$ and thermostability, some alginate lyases also display positive traits for the preparation of alginate oligomers with different degrees of polymerisation. For example, Alg2A from Flavobacterium sp. S20 can produce high yields of oligosaccharides with a high degree of 
polymerisation (e.g. penta-, hexa- and hepta-saccharides) [105].

Despite increasing numbers of identified enzymes for the production of marine polysaccharides (e.g. alginate), our understanding of marine enzymatic activity and mechanisms is lacking compared with that of terrestrial enzymes. However, rapid growth in the number of marine-derived enzymes and "multi-omics" data make it possible to obtain potential commercial enzymes for macroalgae degradation by not only identifying new enzymes with excellent capability from natural environments, but also rational design combined with machine and deep learning approaches. Using powerful computational approaches, alginate lyases may be customised to produce oligomers with fixed numbers of units. Likewise, multifunctional alginate lyases with completely different catalytic functions can also be designed. For example, PL17 alginate lyase Smlt2602 from Stenotrophomonas maltophilia K279a exhibits a unique property and provides an important clue to developing multifunctional enzymes [106]. When its His208 residue was changed to Phe208, the resulting H208F mutant displayed significant catalytic activity toward glucuronan, a non-alginatebased substrate [106]. This was also the first alginate lyase capable of exolytic glucuronan activity. However, the mechanism leading to the digestive turnover of two different substrates is unclear, and crystal structures of Smlt2602 and H208F bound to their respective substrates are required.

\section{Combined enzymes for AOS preparation}

Besides single enzymes, different types of alginate lyases can produce AOS synergistically (Fig. 5B). For example, combining alginate lyase AlyPB1 with oligo-alginate lyase AlyPB2 is more efficient for AOS formation due to synergistic digestion [107]. In addition to combining alginate lyases, a mixture of different enzyme classes may be more favourable. Li et al. reported a rapid and efficient method for producing AOS directly from brown algae via tandem usage of cellulase and alginate lyase [108]. First, dried algae powder is digested by cellulase to release the fermentable sugars glucose and mannitol. Subsequently, the yeast strain Yarrowia lipolytica expressing an extracellular alginate lyase is fermented with cellulase-pretreated algae medium. During fermentation, glucose and mannitol are consumed while AOS are released into the supernatant [108]. The improvement in brown algae-degrading efficiency in vitro may also be compatible with terrestrial carbohydrate materials [109], hence it may be possible to tailor-make a set of substrate-associated enzymes. This approach is very common in the enzymatic hydrolysis of many agricultural residues such as rice straw [110], wheat straw [111], corn stover [112] and sugarcane bagasse
[113]. It combines a biochemical approach with mathematical analysis to develop an efficient and mixed customised enzymatic system.

\section{Applications and prospects of alginolytic pathways Engineering of industrial microbes}

Because common industrial microorganisms cannot utilise alginate due to the lack of an alginate metabolic pathway, it was impossible to achieve a complete conversion from brown algae to ethanol until 2012 when Wargacki et al. [7] engineered an appropriate microbial platform (Fig. 5C). In this platform, E. coli is used as a host, and alginate lyase SM0524Aly from Pseudoalteromonas sp. SM0524 is secreted by an autotransporter. In addition, a large gene cluster encoding alginate metabolism enzymes in $V$. splendidus 12B01 was introduced, accompanied by other auxiliary candidates for complete alginate degradation. Finally, to produce ethanol, a heterologous pathway containing a pyruvate decarboxylase (Pdc) and an alcohol dehydrogenase $\mathrm{B}$ (AdhB) was integrated into the E. coli chromosome, while endogenous $E$. coli genes responsible for the formation of fermentative by-products were deleted. Using the platform, the fermentative yield with alginate, mannitol and glucan reached $0.28 \mathrm{~g}$ ethanol per g dry brown algae, over $80 \%$ of the maximum theoretical yield [7]. Subsequently, Yoshikuni and co-workers developed a more stable system through recombinaseassisted genome engineering (RAGE) to produce ethanol directly from brown algae [114]. Using this system, a heterologous gene cluster for alginate metabolism was integrated into the E. coli chromosome, leading to a $\sim 40 \%$ improvement in ethanol yield compared with the plasmid-based counterpart. Meanwhile, the integrated alginate pathway displayed stable phenotypes over 50 generations, with $E$. coli cells reaching slightly higher productivities than the original inocula [114].

In 2014, Enquist-Newman et al. attempted to produce ethanol in a safer microbe, Saccharomyces cerevisiae [8]. Apart from an active transporter for DEH, genes originating from bacteria were codon-optimised for the stepwise conversion of DEH to pyruvate in $S$. cerevisiae, including dheR, $k d g K$, and KDPG aldolase gene $k d g A$. To solve the problem of DEH import, eukaryotic DEH transporter DHT1 from the deuteromycete Asteromyces cruciatus was identified to be critical for DEH entry. Additionally, the native mannitol catabolism genes encoding mannitol-2-dehydrogenase and a mannitol transporter were overexpressed to efficiently metabolise mannitol. Using this platform, the ethanol yield supplemented with DEH and mannitol was up to $4.6 \% \mathrm{v} / \mathrm{v}$ (Table 1 ), approximately $83 \%$ of the maximum theoretical yield [8]. 
Table 1 The ethanol yield of different microorganisms

\begin{tabular}{|c|c|c|c|c|c|}
\hline Microorganism & Characteristics & Major sugars utilised & Pretreatment & Productivity of ethanol & Reference \\
\hline Escherichia coli BAL1611 & Engineered strain & Mannitol, alginate, glucose & No pretreatment & $0.28 \mathrm{~g} \mathrm{~g}^{-1}$ powder of kelp & [7] \\
\hline $\begin{array}{l}\text { Saccharomyces cerevisiae } \\
\text { BAL3215 }\end{array}$ & Engineered strain & Mannitol, DEH & N/A & $\begin{array}{l}0.22 \mathrm{~g} \mathrm{~g}^{-1} \mathrm{DEH} \text { and mannitol } \\
(1: 2 \text { molar ratio })\end{array}$ & [8] \\
\hline Saccharomyces cerevisiae AM1 & Engineered strain & Mannitol, DEH & N/A & $\begin{array}{l}0.15 \mathrm{~g} \mathrm{~g}-1 \text { alginate and mannitol } \\
(1: 2 \text { molar ratio })\end{array}$ & [125] \\
\hline $\begin{array}{l}\text { Saccharomyces cerevisiae } \\
\text { MK5622 }\end{array}$ & Engineered strain & DEH & N/A & $0.12 \mathrm{~g} \mathrm{~g}^{-1} \mathrm{DEH}$ & [116] \\
\hline Sphingomonas sp. A1 & Engineered strain & Alginate & N/A & $0.26 \mathrm{~g} \mathrm{~g}^{-1}$ alginate & {$[117]$} \\
\hline Vibrio sp. dhg & Engineered strain & Mannitol, alginate & No pretreatment & $0.35 \mathrm{~g} \mathrm{~g}^{-1}$ powder of kelp & [119] \\
\hline Defluviitalea phaphyphila Alg1 & Natural strain & Mannitol, alginate, laminarin & No pretreatment & $0.25 \mathrm{~g} \mathrm{~g}^{-1}$ powder of kelp & [126] \\
\hline Clostridium phytofermentans & Natural strain & Alginate & Acid pretreatment & $0.05 \mathrm{~g} \mathrm{~g}^{-1}$ alginate & [120] \\
\hline
\end{tabular}

Later, an alginate-utilising S. cerevisiae recombinant strain was constructed by chromosomal integration of genes encoding alginate degradation proteins, and at the same time, the mannitol-utilising capacity was enhanced by prolonged growth with mannitol as the sole carbon source [115]. This engineered S. cerevisiae strain was capable of directly producing bioethanol from mannitol and alginate, although ethanol yields were not very high $\left(8.8 \mathrm{~g} \mathrm{~g}^{-1}\right.$ mixture of alginate and mannitol, $\sim 32 \%$ of the maximum theoretical yield; Table 1). Meanwhile, Matsuoka et al. constructed two engineered S. cerevisiae strains and further improved their aerobic growth in DEH liquid medium through adaptive evolution [116]. Among different mutations in both evolved strains, an E17G mutation in the codon-optimised NAD(P)H-dependent DEH reductase was proposed to be essential for both enhanced activity of DEH reductase and aerobic growth [116].

\section{Engineering of native alginate-assimilating microbes}

Besides the engineered alginate pathway in industrial microbes, some alginate-utilising bacteria per se show great potential for the bioconversion of brown algae. Sphingomonas sp. A1 was the first engineered native microbial platform to produce ethanol from alginate [117]. Two heterogeneous genes encoding Pdc and Adh from Zymomonas mobilis were introduced and overexpressed in Sphingomonas sp. A1, and the lactate by-product synthesis pathway was blocked to increase ethanol productivity (resulting in Sphingomonas sp. A1 ethanologenic strain MK3353). After a 3-day incubation, the ethanol yield was $0.26 \mathrm{~g} \mathrm{~g}^{-1}$ alginate. However, because MK3353 is unable to grow under anaerobic conditions, the tricarboxylic acid (TCA) cycle can consume pyruvate, and thus compete with ethanol production [117]. Later, Fujii et al. found that toxic by-products accumulated and inhibited the growth of MK3353 during ethanol fermentation from alginate, which was partially overcome by $\mathrm{pH}$ adjustment [118].

In 2019, the fast-growing Vibrio sp. dhg strain was engineered, and reported to be capable of degrading alginate [119]. Bioinformatic analysis revealed that Vibrio sp. dhg contained both alginate and mannitol metabolic pathways. Based on this, different strategies were adopted to generate different products from brown algae sugar mixtures, such as ethanol, 2,3-butanediol and lycopene [119] (Fig. 5C, left panel). In this platform, transcription and translation related to the degradation of polysaccharide substrates can be controlled, and many genetic circuits used in E. coli are available [119], which together make this strain promising for further applications. Notably, engineered Vibrio sp. dhg displayed the highest ethanol yield (0.35 $\left.\mathrm{g} \mathrm{g}^{-1} \mathrm{kelp}\right)$ among all reported microorganisms that converted alginate to ethanol (Table 1).

The Firmicutes bacterium D. phaphyphila isolated from coastal sediment may be the first characterised microorganism capable of directly converting alginate to ethanol $[92,93]$. In its genome, a complete ethanol synthesis pathway is present, including many genes related to alginate degradation, mannitol metabolism, Embden-Meyerhof-Parnas pathway (EMP), EntnerDoudoroff (ED) pathway, and aldehyde dehydrogenases (Fig. 5C, left panel, [92, 93]). Therefore, unlike other microorganisms in which it is hard to control redox homeostasis from metabolism assimilation under anaerobic conditions, D. phaphyphila Alg1 can balance the reducing equivalents in fermenting brown algae via two complementary pathways (alginate and mannitol metabolism pathways) [92, 93]. However, it is not clear how this strain regulates the reducing equivalents precisely. In addition, this strain has at least two inherent advantages for ethanol production: (i) direct utilisation of pretreated brown algae with a comparatively high ethanol yield of $0.25 \mathrm{~g} \mathrm{~g}^{-1} \mathrm{kelp}$, and (ii) a 
thermostable alginolytic system up to $60{ }^{\circ} \mathrm{C}[92,93]$. Recently, the anaerobic Firmicutes strain Clostridium phytofermentans was also found to convert alginate directly from brown algae directly to ethanol [120]. However, genetic tools have not been developed for these microorganisms. Therefore, effective genetic tools may be required to understand and consequently improve alginate and related metabolic pathways, and to elevate the yields of ethanol and other high-value biochemical products.

\section{Microbial consortia}

In addition to engineering single microbes for the production of ethanol and other biochemicals, a co-culture platform was developed for producing ethanol directly from brown macroalgae [121]. In this system, two types of engineered S. cerevisiae strains, one for mannitol and alginate assimilation and the other for cellulase synthesis, were supplied to ferment macroalgae Ecklonia kurome, and ethanol production reached $0.17 \mathrm{~g} \mathrm{~g}^{-1}$ mixture of alginate and mannitol [121]. This approach is the only reported system to apply a microbial consortium for alginate utilisation, and it has advantages for efficient utilisation of varying amounts of carbohydrate components in brown macroalgae through adjusting the ratio of co-culturing yeasts. Although few data about modular microbial co-cultivating approaches are available for bioethanol production from macroalgae, a variety of chemical compounds have been produced from terrestrial carbohydrates using microbial consortia for metabolic engineering $[122,123]$. These successful cases will certainly provide valuable hints for further improvements in the bioconversion of macroalgae-derived carbohydrates.

\section{Conclusions and perspectives}

Alginates, major components of brown macroalgae, have attracted much attention for biorefining. Exciting developments include the discovery of alginate lyases with excellent biochemical properties, and the bioconversion of ethanol and other commercial chemicals from alginate, albeit on a laboratory scale (Fig. 5). Compared with longterm research on enzymes and metabolic pathways for the utilisation of terrestrial carbohydrates, understanding enzymes (e.g. alginate lyases) related to macroalgae degradation is just beginning. There are many challenges related to alginate lyases and associated metabolic pathways before industrial application. First, the variable structures of alginate are not fully unlocked, making the understanding of enzymatic action mechanisms more complicated. Furthermore, the catalytic patterns of alginate lyases are not fully elucidated. Except for some PL families with crystal structures, only a limited number of alginate lyase enzyme topologies have been determined, and none are available for recently discovered families such as PL32 and PL34.

Regarding the application of alginate and brown algae, the potential of alginate lyases and related metabolic pathways for biorefining has been demonstrated. However, establishment of a universal approach for industrial bioconversion of brown algae has not been reported. This may reflect comparatively little research on alginate pathways. As mentioned above, although numerous alginate lyases are capable of poly- and/or oligo-alginate degradation in vitro, their roles in vivo remain unknown due to a lack of operable genetic methods for some native alginate-degrading microbes (e.g. D. phaphyphila [93] and $C$. phytofermentans [120]), or detailed metabolic and regulation models for ubiquitous microbes, especially those with the scattered system (e.g. Vibrio [7, 119]). Therefore, these detailed functional investigations will allow the engineering of effective native ethanol-producing systems, as well as the modulation of alginate and other associated metabolic pathways to balance fermentation. In addition, with advancements in omics approaches and an increased understanding of alginate utilisation, microbiome engineering, a new concept referred to as "leveraging fundamental scientific principles and quantitative design to create microbiomes that perform desired functions" [124], might be also applied for bioconversion of brown macroalgae in the future.

\section{Abbreviations}

M: $\beta$-D Mannuronic acid; G: a-L Guluronic acid; $\triangle$ ManUA: 4,5-Unsaturated uronic acid monomers mannuronate; $\triangle$ GulUA: 4,5-Unsaturated uronic acid monomers glucuronate; CBM: Carbohydrate-binding modules; PL: Polysaccharide lyase; PUL: Polysaccharide utilisation loci; DEH: 4-Deoxy-L-erythro5-hexoseulose urinate; KDG: 2-Keto-3-dexy-gluconate; KDPG: Keto-deoxyphospho-gluconate; G-3-P: Glyceraldehyde triphosphate; ABC: ATP-binding cassette; AOS: Alginate oligosaccharides; RAGE: Recombinase-assisted genome engineering.

\section{Supplementary Information}

The online version contains supplementary material available at https://doi. org/10.1186/s13068-021-02007-8.

Additional file 1 Figure S1. Sequence profiles of different PL6 subfamilies. Figure S2. Sequence profiles of PL15, PL17, PL36 and PL39 families. Table S1 Characteristics of alginate lyases.

\section{Acknowledgements}

We are grateful to Dr. Wu, Xiuyun for thoughtful comments and suggestions on sequence profile analyses. This work was supported by the National Natural Science Foundation of China (No. 41706165), the Fundamental Research Funds of Shandong University (No. 2019HW022), and the Source Innovation Foundation for Young Scientists of Qingdao (Grant No. 18-2-2-60-jch). 


\section{Authors' contributions}

$L Z, X L, X Z, Y L$ and $L W$ contributed to the writing of this review. All authors read and approved the final manuscript.

\section{Funding}

This work was supported by the National Natural Science Foundation of China (No. 41706165), the Fundamental Research Funds of Shandong University (No. 2019HW022), and the Source Innovation Foundation for Young Scientists of Qingdao (Grant No. 18-2-2-60-jch).

\section{Availability of data and materials}

Not applicable.

\section{Declarations}

Ethics approval and consent to participate Not applicable.

\section{Consent for publication}

Not applicable.

\section{Competing interests}

The authors declare that they have no competing interests.

Received: 7 May 2021 Accepted: 4 July 2021

Published online: 18 July 2021

\section{References}

1. United Nations DoEaSA, Population Division. World Population Prospects 2019: Highlights (ST/ESA/SER.A/423). 2019. https://www.un.org/ development/desa/pd/node/1114

2. Jung KA, Lim SR, Kim Y, Park JM. Potentials of macroalgae as feedstocks for biorefinery. Bioresource Technol. 2013;135:182-90.

3. Liu J, Yang SQ, Li XT, Yan QJ, Reaney MJT, Jiang ZQ. Alginate oligosaccharides: production, biological activities, and potential applications. Compr Rev Food Sci F. 2019;18:1859-81.

4. Muhama II, Zulkifli N, Selvakumaran SAP, Lazim NAM. Bioactive algalderived polysaccharides: multi-functionalization, therapeutic potentia and biomedical applications. Curr Pharm Design. 2019;25:1147-62.

5. Zargarzadeh M, Amaral AJR, Custodio CA, Mano JF. Biomedical applications of laminarin. Carbohyd Polym. 2020. https://doi.org/10.1016/j. carbpol.2019.115774.

6. Yugay YA, Usoltseva RV, Silant'ev VE, Egorova AE, Karabtsov AA, Kumeiko W , et al. Synthesis of bioactive silver nanoparticles using alginate, fucoidan and laminaran from brown algae as a reducing and stabilizing agent. Carbohyd Polym. 2020. https://doi.org/10.1016/j.carbpol.2020. 116547.

7. Wargacki AJ, Leonard E, Win MN, Regitsky DD, Santos CNS, Kim PB, et al. An engineered microbial platform for direct biofuel production from brown macroalgae. Science. 2012;335:308-13.

8. Enquist-Newman M, Faust AME, Bravo DD, Santos CNS, Raisner RM, Hanel A, et al. Efficient ethanol production from brown macroalgae sugars by a synthetic yeast platform. Nature. 2014;505:239-43.

9. Usov Al, Bilan MI, Klochkova NG. Polysaccharides of algae. 48. Polysaccharide composition of several calcareous red algae-isolation of alginate from Corallina Pilulifera P-Et-R (Rhodophyta, Corallinaceae). Bot Mar. 1995:38:43-51.

10. Jain $\mathrm{S}$, Ohman DE. Role of an alginate lyase for alginate transport in mucoid Pseudomonas aeruginosa. Infect Immun. 2005:73:6429-36.

11. Gimmestad M, Ertesvag H, Heggeset TMB, Aarstad O, Svanem BIG, Valla S. Characterization of three new Azotobacter vinelandii alginate lyases, one of which is involved in cyst germination. J Bacteriol. 2009;191:4845-53.

12. Maunders E, Welch M. Matrix exopolysaccharides; the sticky side of biofilm formation. FEMS Microbiol Lett. 2017. https://doi.org/10.1093/ femsle/fnx120.

13. Wood LF, Ohman DE. Identification of genes in the $\sigma^{22}$ regulon of Pseudomonas aeruginosa required for cell envelope homeostasis in either the planktonic or the sessile mode of growth. MBio. 2012. https://doi. org/10.1128/mBio.00094-12.

14. Urtuvia V, Maturana N, Acevedo F, Peña C, Díaz-Barrera A. Bacterial alginate production: an overview of its biosynthesis and potential industrial production. World J Microb Biot. 2017;33:87.

15. Baker P, Ricer T, Moynihan PJ, Kitova EN, Walvoort MTC, Little DJ, et al. $P$. aeruginosa SGNH hydrolase-like proteins AlgJ and AlgX have similar topology but separate and distinct roles in alginate acetylation. Plos Pathog. 2014. https://doi.org/10.1371/journal.ppat.1004334.

16. Skjåk-Bræk G, Paoletti S, Gianferrara T. Selective acetylation of mannuronic acid residues in calcium alginate gels. Carbohyd Res. 1989;185:119-29.

17. Wong TY, Preston LA, Schiller NL. Alginate lyase: review of major sources and enzyme characteristics, structure-function analysis, biological roles, and applications. Annu Rev Microbiol. 2000;54:289-340.

18. Skjakbraek G, Zanetti F, Paoletti S. Effect of acetylation on some solution and gelling properties of alginates. Carbohyd Res. 1989;185:131-8. https://doi.org/10.1016/0008-6215(89)84028-5.

19. Skjåk-Bræk G, Donati I, Paoletti S. Alginate hydrogels: properties and applications. In: Matricardi P, Alhaique F, Coviello T, editors. Polysaccharide hydrogels: characterization and biomedical applications. Singapore: Pan Stanford Publishing Pte Ltd; 2015.

20. Braccini I, Perez S. Molecular basis of $\mathrm{Ca}^{2+}$-induced gelation in alginates and pectins: the egg-box model revisited. Biomacromol. 2001:2:1089-96.

21. Ertesvåg H. Alginate-modifying enzymes: biological roles and biotechnological uses. Front Microbiol. 2015;6:523. https://doi.org/10.3389/ fmicb.2015.00523.

22. Itoh T, Nakagawa E, Yoda M, Nakaichi A, Hibi T, Kimoto H. Structural and biochemical characterisation of a novel alginate lyase from Paenibacillus sp. Str. FPU-7. Sci Rep. 2019:9:54.

23. Helbert W, Poulet L, Drouillard S, Mathieu S, Loiodice M, Couturier M, et al. Discovery of novel carbohydrate-active enzymes through the rational exploration of the protein sequences space. P Natl Acad Sci USA. 2019:116:10184-5.

24. Ji SQ, Dix SR, Aziz AA, Sedelnikova SE, Baker PJ, Rafferty JB, et al. The molecular basis of endolytic activity of a multidomain alginate lyase from Defluviitalea phaphyphila, a representative of a new lyase family, PL39. J Biol Chem. 2019;294:18077-91.

25. Qin HM, Miyakawa T, Inoue A, Nishiyama R, Nakamura A, Asano A, et al. Structure and polymannuronate specificity of a eukaryotic member of polysaccharide lyase family 14. J Biol Chem. 2017:292:2182-90.

26. Suzuki H, Suzuki K, Inoue A, Ojima T. A novel oligoalginate lyase from abalone, Haliotis discus hannai, that releases disaccharide from alginate polymer in an exolytic manner. Carbohyd Res. 2006;341:1809-19.

27. Rahman MM, Inoue A, Tanaka H, Ojima T. cDNA cloning of an alginate lyase from a marine gastropod Aplysia kurodai and assessment of catalytically important residues of this enzyme. Biochimie. 2011;93:1720-30.

28. Rahman MM, Wang L, Inoue A, Ojima T. cDNA cloning and bacterial expression of a PL-14 alginate lyase from a herbivorous marine snail Littorina brevicula. Carbohyd Res. 2012;360:69-77.

29. Ogura K, Yamasaki M, Yamada T, Mikami B, Hashimoto W, Murata K. Crystal structure of family 14 polysaccharide lyase with $\mathrm{pH}$-dependent modes of action. J Biol Chem. 2009;284:35572-9.

30. Cheng D, Jiang C, Xu J, Liu Z, Mao X. Characteristics and applications of alginate lyases: a review. Int J Biol Macromol. 2020;164:1304-20. https:// doi.org/10.1016/j.ijbiomac.2020.07.199.

31. Thomas F, Lundqvist LCE, Jam M, Jeudy A, Barbeyron T, Sandstrom C, et al. Comparative characterization of two marine alginate lyases from Zobellia galactanivorans reveals distinct modes of action and exquisite adaptation to their natural substrate. J Biol Chem. 2013;288:23021-37.

32. Tang LY, Wang Y, Gao S, Wu H, Wang DN, Yu WG, et al. Biochemical characteristics and molecular mechanism of an exo-type alginate lyase VxAly7D and its use for the preparation of unsaturated monosaccharides. Biotechnol Biofuels. 2020;13:247.

33. Hashimoto W, Miyake O, Momma K, Kawai S, Murata K. Molecular identification of oligoalginate lyase of Sphingomonas sp. strain A1 as one of the enzymes required for complete depolymerization of alginate. J Bacteriol. 2000;182:4572-7. https://doi.org/10.1128/Jb.182.16.45724577.2000 . 
34. Miyake O, Hashimoto W, Murata K. An exotype alginate lyase in Sphingomonas sp. Al: overexpression in Escherichia coli, purification, and characterization of alginate lyase IV (A1-IV). Protein Expres Purif. 2003;29:33-41.

35. Huang G, Wen S, Liao S, Wang Q, Pan S, Zhang R, et al. Characterization of a bifunctional alginate lyase as a new member of the polysaccharide lyase family 17 from a marine strain BP-2. Biotechnol Lett. 2019;41:1187-200. https://doi.org/10.1007/s10529-019-02722-1.

36. Park HH, Kam N, Lee EY, Kim HS. Cloning and Characterization of a novel oligoalginate lyase from a newly isolated bacterium Sphingomonas sp. MJ-3. Mar Biotechnol. 2011;14:189-202. https://doi.org/10.1007/ s10126-011-9402-7.

37. Miyake O, Ochiai A, Hashimoto W, Murata K. Origin and diversity of alginate lyases of families PL-5 and -7 in Sphingomonas sp. strain A1.J Bacteriol. 2004;186:2891-6. https://doi.org/10.1128/jb.186.9.2891-2896. 2004

38. Dudek M, Dieudonne A, Jouanneau D, Rochat T, Michel G, Sarels B, et al. Regulation of alginate catabolism involves a GntR family repressor in the marine flavobacterium Zobellia galactanivorans DsijT. Nucleic Acids Res. 2020;48:7786-800.

39. Li SY, Yang XM, Bao MM, Wu Y, Yu WG, Han F. Family 13 carbohydratebinding module of alginate lyase from Agarivorans sp. L11 enhances its catalytic efficiency and thermostability, and alters its substrate preference and product distribution. FEMS Microbiol Lett. 2015:362:348.

40. Zhang ZL, Tang LY, Bao MM, Liu ZG, Yu WG, Han F. Functional characterization of carbohydrate binding modules in a new alginate lyase, TsAly7B, from Thalassomonas sp. LD5. Mar Drugs. 2020;18:1247.

41. Han WJ, Gu JY, Cheng YY, Liu HH, Li YZ, Li FC. Novel alginate lyase (Aly5) from a polysaccharide-degrading marine bacterium, Flammeovirga sp. strain MY04: Effects of module truncation on biochemical characteristics, alginate degradation patterns, and oligosaccharide-yielding properties. Appl Environ Microb. 2016;82:364-74.

42. Yan JJ, Chen P, Zeng Y, Men Y, Mu SC, Zhu YM, et al. The characterization and modification of a novel bifunctional and robust alginate lyase derived from Marinimicrobium sp. H1. Mar Drugs. 2019;17:258.

43. Yang M, Li NN, Yang SX, Yu Y, Han ZL, Li L, et al. Study on expression and action mode of recombinant alginate lyases based on conserved domains reconstruction. Appl Microbiol Biot. 2019;103:807-17.

44. Sim PF, Furusawa G, Teh AH. Functional and structural studies of a multidomain alginate lyase from Persicobacter sp. CCB-QB2. Sci Rep. $2017 ; 7: 64$

45. Zhuang JJ, Zhang KK, Liu XH, Liu WZ, Lyu QQ, Ji AG. Characterization of a novel polyM-preferred alginate lyase from marine Vibrio splendidus OU02. Mar Drugs. 2018;16:52.

46. Hu F, Li Q, Zhu BW, Ni F, Sun Y, Yao Z. Effects of module truncation on biochemical characteristics and products distribution of a new alginate lyase with two catalytic modules. Glycobiology. 2019;29:876-84

47. Xu F, Wang P, Zhang YZ, Chen XL. Diversity of three-dimensional structures and catalytic mechanisms of alginate lyases. Appl Environ Microb. 2018;84:47.

48. Xu F, Chen XL, Sun XH, Dong F, Li CY, Li PY, et al. Structural and molecular basis for the substrate positioning mechanism of a new PL7 subfamily alginate lyase from the Arctic. J Biol Chem. 2020. https://doi.org/10. 1074/jbc.RA120.015106.

49. Yoon HJ, Hashimoto W, Miyake O, Murata K, Mikami B. Crystal structure of alginate lyase A1-III complexed with trisaccharide product at 2.0 angstrom resolution. J Mol Biol. 2001;307:9-16.

50. Ochiai A, Yamasaki M, Mikami B, Hashimoto W, Murata K. Crystal structure of exotype alginate lyase Atu3025 from Agrobacterium tumefaciens. J Biol Chem. 2010;285:24519-28.

51. Park D, Jagtap S, Nair SK. Structure of a PL17 family alginate lyase demonstrates functional similarities among exotype depolymerases. J Biol Chem. 2014;289:8645-55.

52. Xu F, Dong F, Wang P, Cao HY, Li CY, Li PY, et al. Novel molecular insights into the catalytic mechanism of marine bacterial alginate lyase AlyGC from polysaccharide lyase family 6. J Biol Chem. 2017;292:4457-68.

53. Stender EGP, Andersen CD, Fredslund F, Holck J, Solberg A, Teze D, et al. Structural and functional aspects of mannuronic acid-specific PL6 alginate lyase from the human gut microbe Bacteroides cellulosilyticus. J Biol Chem. 2019;294:17915-30.
54. Lyu QQ, Zhang KK, Shi YH, Li WH, Diao XT, Liu WZ. Structural insights into a novel $\mathrm{Ca}^{2+}$-independent PL-6 alginate lyase from Vibrio OU02 identify the possible subsites responsible for product distribution. BBAGen Subjects. 2019;1863:1167-76.

55. Garron ML, Cygler M. Structural and mechanistic classification of uronic acid-containing polysaccharide lyases. Glycobiology. 2010;20:1547-73.

56. Mikami B, Ban M, Suzuki S, Yoon HJ, Miyake O, Yamasaki M, et al. Induced-fit motion of a lid loop involved in catalysis in alginate lyase A1-III. Acta Crystallogr D Biol Crystallogr. 2012;68:1207-16. https://doi. org/10.1107/S090744491202495X.

57. Wu X, Tian Z, Jiang X, Zhang Q, Wang L. Enhancement in catalytic activity of Aspergillus niger XynB by selective site-directed mutagenesis of active site amino acids. Appl Microbiol Biotechnol. 2018;102:249-60. https://doi.org/10.1007/s00253-017-8607-8.

58. Wu XY, Zhang Q, Zhang LZ, Liu S, Chen GJ, Zhang HQ, et al. Insights into the role of exposed surface charged residues in the alkali-tolerance of GH11 xylanase. Front Microbiol. 2020;11:8.

59. Yamasaki M, Ogura K, Hashimoto W, Mikami B, Murata K. A structural basis for depolymerization of alginate by polysaccharide lyase family-7. J Mol Biol. 2005:352:11-21.

60. Qin HM, Miyakawa T, Inoue A, Nishiyama R, Nakamura A, Asano A, et al. Structural basis for controlling the enzymatic properties of polymannuronate preferred alginate lyase FIAlyA from the PL-7 family. Chem Commun. 2018;54:555-8. https://doi.org/10.1039/c7cc06523j.

61. Sim PF, Furusawa G, Teh AH. Functional and structural studies of a multidomain alginate lyase from Persicobacter sp. CCB-QB2. Sci Rep. 2017:7:13656. https://doi.org/10.1038/s41598-017-13288-1.

62. Dong F, Xu F, Chen XL, Li PY, Li CY, Li FC, et al. Alginate lyase Aly36B is a new bacterial member of the polysaccharide lyase family 36 and catalyzes by a novel mechanism with lysine as both the catalytic base and catalytic acid. J Mol Biol. 2019;431:4897-909.

63. Maruyama Y, Hashimoto W, Murata K. Structural studies on bacterial system used in the recognition and uptake of the macromolecule alginate. Biosci Biotech Bioch. 2019;83:794-802.

64. Bjursell MK, Martens EC, Gordon Jl. Functional genomic and metabolic studies of the adaptations of a prominent adult human gut symbiont, Bacteroides thetaiotaomicron, to the suckling period. J Biol Chem. 2006;281:36269-79

65. Hobbs JK, Lee SM, Robb M, Hof F, Barr C, Abe KT, et al. KdgF, the missing link in the microbial metabolism of uronate sugars from pectin and alginate. Proc Natl Acad Sci USA. 2016;113:6188-93.

66. Terrapon N, Lombard V, Gilbert HJ, Henrissat B. Automatic prediction of polysaccharide utilization loci in Bacteroidetes species. Bioinformatics. 2015;31:647-55.

67. Lapebie P, Lombard V, Drula E, Terrapon N, Henrissat B. Bacteroidetes use thousands of enzyme combinations to break down glycans. Nat Commun. 2019. https://doi.org/10.1038/s41467-019-10068-5.

68. Glenwright AJ, Pothula KR, Bhamidimarri SP, Chorev DS, Basle A, Firbank SJ, et al. Structural basis for nutrient acquisition by dominant members of the human gut microbiota. Nature. 2017;541:407-11.

69. Hemsworth GR, Dejean G, Davies GJ, Brumer H. Learning from microbial strategies for polysaccharide degradation. Biochem Soc T. 2016:44:94-108.

70. Badur AH, Jagtap SS, Yalamanchili G, Lee JK, Zhao H, Rao CV. Alginate lyases from alginate-degrading Vibrio splendidus 12B01 are endolytic. Appl Environ Microbiol. 2015;81:1856-64.

71. Jagtap SS, Hehemann JH, Polz MF, Lee JK, Zhao HM. Comparative biochemical characterization of three exolytic oligoalginate lyases from Vibrio splendidus reveals complementary substrate scope, temperature, and pH adaptations. Appl Environ Microb. 2014;80:4207-14.

72. Hashimoto W, He JS, Wada Y, Nankai H, Mikami B, Murata K. Proteomics-based identification of outer-membrane proteins responsible for import of macromolecules in Sphingonionas sp. A1: Alginate-binding flagellin on the cell surface. Biochemistry. 2005;44:13783-94.

73. Kabisch A, Otto A, Konig S, Becher D, Albrecht D, Schuler M, et al. Functional characterization of polysaccharide utilization loci in the marine Bacteroidetes "Gramella forsetii" KT0803. ISME J. 2014;8:1492-502.

74. Kappelmann L, Kruger K, Hehemann JH, Harder J, Markert S, Unfried F, et al. Polysaccharide utilization loci of North Sea Flavobacteriia 
as basis for using SusC/D-protein expression for predicting major phytoplankton glycans. ISME J. 2019;13:76-91.

75. Thomas F, Barbeyron T, Tonon T, Genicot S, Czjzek M, Michel G. Characterization of the first alginolytic operons in a marine bacterium: from their emergence in marine Flavobacteriia to their independent transfers to marine Proteobacteria and human gut Bacteroides. Environ Microbiol. 2012;14:2379-94.

76. Thomas F, Bordron P, Eveillard D, Michel G. Gene expression analysis of Zobellia galactanivorans during the degradation of algal polysaccharides reveals both substrate-specific and shared transcriptomewide responses. Front Microbiol. 2017;8:35.

77. Nishiyama R, Inoue A, Ojima T. Identification of 2-keto-3-deoxy-Dgluconate kinase and 2-keto-3-deoxy-D-phosphogluconate aldolase in an alginate-assimilating bacterium, Flavobacterium sp. strain UMI01. Mar Drugs. 2017;15:9112.

78. Mann AJ, Hahnke RL, Huang SX, Werner J, Xing P, Barbeyron T, et al. The genome of the alga-associated marine flavobacterium Formosa agariphila KMM $3901^{\top}$ reveals a broad potential for degradation of algal polysaccharides. Appl Environ Microb. 2013;79:6813-22.

79. Mathieu S, Touvrey-Loiodice M, Poulet L, Drouillard S, Vincentelli R, Henrissat $B$, et al. Ancient acquisition of "alginate utilization loci" by human gut microbiota. Sci Rep. 2018;8:329.

80. Garcia-Martinez J, Acinas SG, Massana R, Rodriguez-Valera F. Prevalence and microdiversity of Alteromonas macleodii-like microorganisms in different oceanic regions. Environ Microbiol. 2002;4:42-50.

81. Gonzaga A, Martin-Cuadrado AB, Lopez-Perez M, Mizuno CM, GarciaHeredia I, Kimes NE, et al. Polyclonality of concurrent natural populations of Alteromonas macleodii. Genome Biol Evol. 2012;4:1360-74.

82. Ivars-Martinez E, D'Auria G, Rodriguez-Valera F, Sanchez-Porro C, Ventosa A, Joint I, et al. Biogeography of the ubiquitous marine bacterium Alteromonas macleodii determined by multilocus sequence analysis. Mol Ecol. 2008;17:4092-106.

83. Neumann AM, Balmonte JP, Berger M, Giebel HA, Arnosti C, Voget $S$, et al. Different utilization of alginate and other algal polysaccharides by marine Alteromonas macleodii ecotypes. Environ Microbiol. 2015;17:3857-68

84. Wietz M, Wemheuer B, Simon H, Giebel HA, Seibt MA, Daniel R, et al. Bacterial community dynamics during polysaccharide degradation at contrasting sites in the Southern and Atlantic Oceans. Environ Microbiol. 2015;17:3822-31.

85. Koch H, Germscheid N, Freese HM, Noriega-Ortega B, Lucking D, Berger M, et al. Genomic, metabolic and phenotypic variability shapes ecological differentiation and intraspecies interactions of Alteromonas macleodii. Sci Rep. 2020;10:648.

86. He JS, Ochiai A, Fukuda Y, Hashimoto W, Murata K. A putative lipoprotein of Sphingomonas sp. strain A1 binds alginate rather than a lipid moiety. FEMS Microbiol Lett. 2008;288:221-6.

87. Maruyama Y, Ochiai A, Mikami B, Hashimoto W, Murata K. Crystal structure of bacterial cell-surface alginate-binding protein with an M75 peptidase motif. Biochem Bioph Res Co. 2011;405:411-6.

88. Temtrirath K, Okumura K, Maruyama Y, Mikami B, Murata K, Hashimoto W. Binding mode of metal ions to the bacterial iron import protein EfeO. Biochem Bioph Res Co. 2017:493:1095-101.

89. Momma K, Mishima Y, Hashimoto W, Mikami B, Murata K. Direct evidence for Sphingomonas sp. A1 periplasmic proteins as macromolecule-binding proteins associated with the $A B C$ transporter: molecular insights into alginate transport in the periplasm. Biochemistry. 2005:44:5053-64.

90. Momma K, Okamoto M, Mishima Y, Mori S, Hashimoto W, Murata K. A novel bacterial ATP-binding cassette transporter system that allows uptake of macromolecules. J Bacteriol. 2000;182:3998-4004.

91. Maruyama Y, Itoh T, Kaneko A, Nishitani Y, Mikami B, Hashimoto W, et al. Structure of a bacterial $A B C$ transporter involved in the import of an acidic polysaccharide alginate. Structure. 2015;23:1643-54.

92. Ji SQ, Wang B, Lu M, Li FL. Defluviitalea phaphyphila sp. Nov., a novel thermophilic bacterium that degrades brown algae. Appl Environ Microb. 2016;82:868-77

93. Ji SQ, Wang B, Lu M, Li FL. Direct bioconversion of brown algae into ethanol by thermophilic bacterium Defluviitalea phaphyphila. Biotechnol Biofuels. 2016;9:224.
94. Zhu YM, Chen P, Bao YJ, Men Y, Zeng Y, Yang JG, et al. Complete genome sequence and transcriptomic analysis of a novel marine strain Bacillus weihaiensis reveals the mechanism of brown algae degradation. Sci Rep. 2016;6:194.

95. Koch H, Durwald A, Schweder T, Noriega-Ortega B, Vidal-Melgosa $\mathrm{S}$, Hehemann $\mathrm{JH}$, et al. Biphasic cellular adaptations and ecological implications of Alteromonas macleodii degrading a mixture of algal polysaccharides. ISME J. 2019;13:92-103.

96. Preheim SP, Timberlake S, Polz MF. Merging taxonomy with ecological population prediction in a case study of Vibrionaceae. Appl Environ Microb. 2011;77:7195-206.

97. Hehemann JH, Arevalo P, Datta MS, Yu XQ, Corzett CH, Henschel A, et al. Adaptive radiation by waves of gene transfer leads to fine-scale resource partitioning in marine microbes. Nat Commun. 2016;7:12860.

98. Reintjes G, Arnosti C, Fuchs B, Amann R. Selfish, sharing and scavenging bacteria in the Atlantic Ocean: a biogeographical study of bacterial substrate utilisation. ISME J. 2019;13:1119-32.

99. Reintjes G, Arnosti C, Fuchs BM, Amann R. An alternative polysaccharide uptake mechanism of marine bacteria. ISME J. 2017;11:1640-50.

100. Mitulla M, Dinasquet J, Guillemette R, Simon M, Azam F, Wietz M. Response of bacterial communities from California coastal waters to alginate particles and an alginolytic Alteromonas macleodii strain. Environ Microbiol. 2016;18:4369-77.

101. Gao J, Lin LZ, Sun BG, Zhao MM. A comparison study on polysaccharides extracted from Laminaria japonica using different methods: structural characterization and bile acid-binding capacity. Food Funct. 2017:8:3043-52.

102. Vuoristo KS, Fredriksen L, Oftebro M, Arntzen MO, Aarstad OA, Stokke R, et al. Production, characterization, and application of an alginate lyase, AMOR_PL7A, from hot vents in the Arctic Mid-Ocean Ridge. J Agr Food Chem. 2019;67:2936-45.

103. Inoue A, Anraku M, Nakagawa S, Ojima T. Discovery of a novel alginate lyase from Nitratiruptor sp. SB155-2 thriving at deep-sea hydrothermal vents and identification of the residues responsible for its heat stability. J Biol Chem. 2016:291:15551-63.

104. Wang YA, Chen XH, Bi XL, Ren YN, Han Q, Zhou Y, et al. Characterization of an alkaline alginate lyase with $\mathrm{pH}$-stable and thermo-tolerance property. Mar Drugs. 2019;17:82.

105. Huang LS, Zhou JG, Li X, Peng Q, Lu H, Du YG. Characterization of a new alginate lyase from newly isolated Flavobacterium sp. S20. J Ind Microbiol Biot. 2013;40:113-22.

106. MacDonald LC, Weiler EB, Berger BW. Engineering broad-spectrum digestion of polyuronides from an exolytic polysaccharide lyase. Biotechnol Biofuels. 2016;9:43.

107. Lu DR, Zhang QD, Wang SM, Guan JW, Jiao RM, Han NH, et al. Biochemical characteristics and synergistic effect of two novel alginate lyases from Photobacterium sp. FC615. Biotechnol Biofuels. 2019:12:54.

108. Li SY, Wang ZP, Wang LN, Peng JX, Wang YN, Han YT, et al. Combined enzymatic hydrolysis and selective fermentation for green production of alginate oligosaccharides from Laminaria japonica. Bioresour Technol. 2019;281:84-9.

109. Zhang S, Zhao Y, Chen GJ, Yu JH, Wu XY, Wang LS. High efficient degradation of biomass polysaccharides and precise customization of degrading enzymes. Prog Biochem Biophy. 2020;4:1-15.

110. Laothanachareon T, Bunterngsook B, Suwannarangsee S, Eurwilaichitr L, Champreda V. Synergistic action of recombinant accessory hemicellulolytic and pectinolytic enzymes to Trichoderma reesei cellulase on rice straw degradation. Bioresour Technol. 2015;198:682-90.

111. Karnaouri A, Matsakas L, Topakas E, Rova U, Christakopoulos P. Development of thermophilic tailor-made enzyme mixtures for the bioconversion of agricultural and forest residues. Front Microbiol. 2016;7:331.

112. Gao DH, Uppugundla N, Chundawat SPS, Yu XR, Hermanson S, Gowda $\mathrm{K}$, et al. Hemicellulases and auxiliary enzymes for improved conversion of lignocellulosic biomass to monosaccharides. Biotechnol Biofuels. 2011;4:5.

113. Kim IJ, Lee HJ, Kim KH. Pure enzyme cocktails tailored for the saccharification of sugarcane bagasse pretreated by using different methods. Process Biochem. 2017:57:167-74.

114. Santos CNS, Regitsky DD, Yoshikuni Y. Implementation of stable and complex biological systems through recombinase-assisted genome engineering. Nat Commun. 2013;4:2503. 
115. Takagi T, Sasaki Y, Motone K, Shibata T, Tanaka R, Miyake H, et al. Construction of bioengineered yeast platform for direct bioethanol production from alginate and mannitol. Appl Microbiol Biot. 2017;101:6627-36.

116. Matsuoka F, Hirayama M, Kashihara T, Tanaka H, Hashimoto W, Murata K, et al. Crucial role of 4-deoxy-L-erythro-5-hexoseulose uronate reductase for alginate utilization revealed by adaptive evolution in engineered Saccharomyces cerevisiae. Sci Rep. 2017;7:54.

117. Takeda H, Yoneyama F, Kawai S, Hashimoto W, Murata K. Bioethanol production from marine biomass alginate by metabolically engineered bacteria. Energ Environ Sci. 2011;4:2575-81.

118. Fujii M, Yoshida S, Murata K, Kawai S. Regulation of pH attenuates toxicity of a byproduct produced by an ethanologenic strain of Sphingomonas sp. A1 during ethanol fermentation from alginate. Bioengineered. 2014:5:38-44.

119. Lim HG, Kwak DH, Park S, Woo S, Yang JS, Kang CW, et al. Vibrio sp. dhg as a platform for the biorefinery of brown macroalgae. Nat Commun. 2019;10:84.

120. Dharshini RS, Fathima AA, Dharani SR, Ramya M. Utilization of alginate from brown macroalgae for ethanol production by Clostridium phytofermentans. Appl Biochem Micro. 2020;56:173-8.

121. Sasaki Y, Takagi T, Motone K, Shibata T, Kuroda K, Ueda M. Direct bioethanol production from brown macroalgae by co-culture of two engineered Saccharomyces cerevisiae strains. Biosci Biotech Bioch. 2018;82:1459-62
122. Lu HY, Villada JC, Lee PKH. Modular metabolic engineering for biobased chemical production. Trends Biotechnol. 2019;37:152-66.

123. Jawed K, Yazdani SS, Koffas MA. Advances in the development and application of microbial consortia for metabolic engineering. Metab Eng Commun. 2019;9: e00095. https://doi.org/10.1016/j.mec.2019. e00095.

124. Lawson CE, Harcombe WR, Hatzenpichler R, Lindemann SR, Loffler FE, O'Malley MA, et al. Common principles and best practices for engineering microbiomes. Nat Rev Microbiol. 2019;17:725-41.

125. Takagi T, Sasaki Y, Motone K, Shibata T, Tanaka R, Miyake H, et al. Construction of bioengineered yeast platform for direct bioethanol production from alginate and mannitol. Appl Microbiol Biotechnol. 2017;101:6627-36. https://doi.org/10.1007/s00253-017-8418-y.

126. Ji SQ, Wang B, Lu M, Li FL. Direct bioconversion of brown algae into ethanol by thermophilic bacterium Defluviitalea phaphyphila. Biotechnol Biofuels. 2016;9:81.

\section{Publisher's Note}

Springer Nature remains neutral with regard to jurisdictional claims in published maps and institutional affiliations.
Ready to submit your research? Choose BMC and benefit from:

- fast, convenient online submission

- thorough peer review by experienced researchers in your field

- rapid publication on acceptance

- support for research data, including large and complex data types

- gold Open Access which fosters wider collaboration and increased citations

- maximum visibility for your research: over $100 \mathrm{M}$ website views per year

At BMC, research is always in progress.

Learn more biomedcentral.com/submissions 